\title{
Qualidade microbiológica e físico-química de queijo minas frescal artesanal e industrial
}

\author{
Bruna Ferreira Dias ${ }^{1}$, Suzane Martins Ferreira ${ }^{2}$, Vania SilvaCarvalho ${ }^{2}$, Dayana Silva Batista \\ Soares $^{2}$
}

\author{
${ }^{1}$ Universidade Federal de Goiás, Campus Samambaia, Goiás, Brasil. E-mail: brunaferreira142011@hotmail.com \\ ${ }^{2}$ Instituto Federal Goiano, Campus Morrinhos, Goiás, Brasil. E-mail: suzane.ferreira@ifgoiano.edu.br, \\ vania.carvalho@ifgoiano.edu.br, dayana.soares@ifgoiano.edu.br
}

Recebido: 15/04/2016; Aceito: 07/07/2016.

\section{RESUMO}

A produção de queijos é uma forma apropriada de conservar o leite, transformando-o em produto mais estável, cujas qualidades são mantidas. No comércio são encontrados queijos Minas frescal nas comercializados industrial e artesanal, e fazem parte da tradição alimentar de todo país, atingindo todas as classes sociais. O presente trabalho avaliou as características físico-químicas, analisou a rotulagem e verificou as condições higiênico sanitárias quanto presença de Salmonella spp; contagem de Staphylococcus aureus, de coliformes termotolerantes e totais de queijos Minas frescal, produzidos industrialmente e artesanalmente na região Sul do estado de Goiás. Foram utilizadas 5 amostras de queijos industrializados, 5 de queijos artesanais comercializados em supermercados. Os resultados revelaram que grande parte das amostras estavam em desacordo com a legislação, quanto a contagem de coliformes totais e termotolerantes apresentando valores superiores a $1100 \mathrm{NMP} / \mathrm{g}$., e a presença de Staphylococcus aureus, havendo ausência de Salmonella spp. Para as análises físico-químicas, os resultados demostraram estar de acordo com a legislação vigente. Quanto à avaliação da conformidade de rotulagem das embalagens, constatou-se que $90 \%$ das amostras industrializadas estavam em acordo com a legislação em vigor e $100 \%$ das artesanais estavam em desacordo. Assim determina-se que de acordo com a legislação vigente os queijos estavam em não conformidade, constatando possíveis falhas no controle da qualidade no processamento e armazenamento dos queijos.

Palavras-chave: Segurança alimentar, contaminação, micro-organismos, qualidade.

\section{Microbiological and physicochemical quality of minas fresh cheese artisanal and industrial}

\section{ABSTRACT}

The production of cheese is an appropriate way of preserving milk, turning it into more stable product, whose qualities are maintained in trade are found industrial and artisanal minas fresh cheese, it is part of the food traditions of the country, reaching all social classes. This study evaluated the physical and chemical characteristics, labeling analyzed and verified the sanitary hygienic as Salmonella spp; enumeration of Staphylococcus aureus, thermos-tolerant coliforms of Minas fresh cheese, industrially produced and handmade in southern Goiás State. We used 5 samples industrialized cheeses, 5 of artisan cheeses sold in supermarkets. The results revealed that most of the samples were in compliance with the legislation, for total coliforms and thermotolerant with values greater than 1100 MPN/g., and the presence of Staphylococcus aureus, with Salmonella spp. For the physicochemical analysis, the results showed comply with current legislation. The assessment of compliance labeling of packages, it was found $90 \%$ of industrialized samples were in accordance with the rules in force and $100 \%$ handmade were at odds. So it is determined that according to law the cheeses were in noncompliance, noting possible failures in controlling the quality of the cheese.

Key words: Food safety, contamination, microrganisms, quality 


\section{Introdução}

Conforme o Regulamento Técnico de Identidade e Qualidade de Produtos Lácteos (BRASIL/MAPA, 1996), entende-se por queijo Minas frescal, o queijo fresco obtido por coagulação enzimática do leite como coalho e/ou outras enzimas coagulantes adaptadas, complementada ou não com a ação de bactérias lácticas especificas. Seguindo a orientação contida nesse regulamento, os queijos tipo Minas frescal podem ser classificados em queijos de baixa umidade ou de massa semidura, com umidade entre 36,0 e $45,9 \%$, queijos de alta umidade ou de massa branda ou "macios", com 46,0 a $54,9 \%$ de umidade e queijos de muita alta umidade ou de massa branda ou "mole", com umidade não inferior a $55,0 \%$.

No Brasil existem vários tipos de queijos frescos produzidos de forma artesanal e industrial, tanto por pequenos produtores quanto por algumas indústrias. Esses queijos são muito populares e devido ao bom rendimento, são comercializados a preço acessível a uma grande faixa da população, por apresentar elevado rentabilidade na fabricação (SENA et al., 2000).

A tecnologia de fabricação de queijo, de modo geral, abrange a coagulação do leite pela adição de fermento lácteo ou ácido láctico ou pelo coalho enzimático, corte, dessoragem, salga úmida e embalagem. A tecnologia empregada desde os primórdios da fabricação de queijo Minas Frescal é a tradicional, onde o uso de fermento lático fornece ao queijo a proteção promovida pelas bactérias láticas. Com objetivo de melhorar o rendimento e diminuição das alterações físico-químicas durante sua vida de prateleira, a tecnologia por acidificação direta foi desenvolvida, com substituição do fermento lático por ácido lático industrial. Segue-se o corte, a dessoragem e a enformagem. A salga pode ser feita por salmoura a $20 \%$ a $10-12{ }^{\circ} \mathrm{C}$. Esse tipo de queijo não sofre processo de cura (CARVALHO, 2007).

No Brasil, tendo em vista à proteção da saúde da população e à qualidade microbiológica dos produtos alimentícios, a Resolução - RDC n 12 da Agência Nacional de Vigilância Sanitária - ANVISA, de 02 de janeiro de 2001, constitui os padrões microbiológicos sanitários para alimentos, em que a tolerância é máxima e os padrões são mínimos para os diferentes grupos de produtos alimentícios, para fins de registro e fiscalização. Para queijos de muita alta umidade (>55\%), como o Minas Frescal, elaborados por coagulação enzimática e sem ação de bactérias lácticas, a legislação brasileira considera uma tolerância de 5,0 $\times$ $10^{2} \mathrm{NMP} / \mathrm{g}$ para coliformes termotolerantes e 5,0 x $10^{2}$ UFC/g para contagem de Staphylococcus aureus e também estabelece ausência de Salmonella spp. e de Listeria monocytogenes em $25 \mathrm{~g}$ desse produto.

Segundo Oliveira (2014), a rotulagem de alimentos permite à população adquirir informações sobre os tipos e as quantidades de nutrientes. Dessa forma, o rótulo pode ser considerado uma ferramenta educativa e eficaz, uma vez que o consumidor pode selecionar alimentos baseando-se em sua informação nutricional e esta prática auxilia na prevenção de doenças e/ou na manutenção da sua saúde. No entanto, para tal desígnio, é indispensável à fidedignidade das informações veiculadas nos rótulos. Tendo em vista as diferentes vias que podem levar à contaminação de queijo Minas frescal e seu alto consumo, são de suma importância a análise microbiológica e a análise de rotulagem desses alimentos como forma de avaliar os perigos que podem representar para a saúde do consumidor.

Objetivou-se com esse trabalho avaliar as características físico-químicas, analisar a rotulagem e verificar as condições higiênico sanitárias quanto a presença de Salmonella spp., a contagem de contagem de Staphylococcus aureus, coliformes termotolerantes e totais de queijos Minas frescal produzidos industrialmente e artesanalmente na região Sul do estado de Goiás.

\section{Material e Métodos}

Os procedimentos metodológicos foram efetuados no Laboratório de Microbiologia do Instituto Federal Goiano, na cidade de Morrinhos (GO). Para a realização deste estudo foram utilizadas 5 amostras de queijos Minas frescal industrilizados, e 5 amostras de queijos artesanais comercializados em supermercado da região Sul de Goiás. Todas as amostras foram coletadas aleatoriamente no período de outubro de 2014, acondicionadas em embalagens individuais. As amostras foram coletadas em sua embalagem plástica original e transportadas sob refrigeração $\left(4 \pm 1{ }^{\circ} \mathrm{C}\right)$, em caixas de isopor com gelo ao Laboratório de Microbiologia, do Instituto Federal Goiano - Câmpus Morrinhos e mantidas sob a mesma temperatura de refrigeração.

Todos os procedimentos utilizados no preparo das amostras seguiram as recomendações descritas por Silva et al. (2001). As embalagens foram desinfectadas com álcool $70 \%$ e abertas com tesoura esterilizada. Com auxílio de uma espátula esterilizada foram retiradas 25 gramas de cada amostra e colocadas em um saco estéril, contendo $225 \mathrm{~mL}$ de água peptonada estéril, homogenizadas por 2 minutos a amostra considerando este a diluição $10^{-1}$. As demais diluições continham 9 $\mathrm{mL}$ de água peptonada e receberam $1 \mathrm{~mL}$ das diluições, tornando $, 10^{-2}, 10^{-3}, 10^{-4}$ e $10^{-5}$, respectivamente.

As análises microbiológicas foram realizadas de acordo com a recomendação e exigências por (APHA, 2001) - American Public Health Association e (FDA, 2007) - Food and Drug Administration, que oficializa 
os métodos analíticos para análises microbiológicas para controle de produtos de origem animal e água.

Foram realizadas análises microbiológicas de pesquisa de Salmonella spp., contagem de coliformes termotolerantes e coliformes totais e contagem de Staphylococcus aureus. E as analises físico-químicas realizadas foram $\mathrm{pH}$, acidez, umidade e teor de $\mathrm{NaCl}$.

Para a contagem de coliformes totais e coliformes termotolerantes foram pesados $25 \pm 0,2 \mathrm{~g}$ da amostra e adicionados $225 \mathrm{~mL}$ de solução salina peptonada $0,1 \%$ $\left(\mathrm{H}_{2} \mathrm{Op}\right)$, homogeneizados por 60 segundos em homogeneizador tipo stomacher e foram efetuadas as demais diluições necessárias. A contagem foi realizada em triplicata nas diluições $10^{-1}, 10^{-2}, 10^{-3}, 10^{-4}, 10^{-5}$, em caldo Lauril Sulfato Triptose (LST) a $35 \pm 0,5^{\circ} \mathrm{C} / 24-48$ $\pm 2 \mathrm{~h}$, em estufa e foi observado se havia crescimento com produção de gás nos tubos. Caso positivo, (crescimento e/ou produção de gás) em seguida foi realizada contagem de coliformes totais, a partir dos tubos de LST transferiu-se uma alçada bem carregada de cada cultura para os tubos de Caldo Verde Brilhante Bile $2 \%$ (VB) e incubados a $35 \pm 0,5{ }^{\circ} \mathrm{C} / 24-48 \pm 2 \mathrm{~h}$. Para a contagem de coliformes termotolerantes a partir dos tubos de LST com produção de gás, transferiu-se uma alçada bem carregada de cada cultura para os tubos de Caldo E. coli e foram incubados a $45,5 \pm 0,2^{\circ} \mathrm{C} / 24 \pm$ $2 \mathrm{~h}$ em banho-maria. Logo após foram anotados os números de tubos com produção de gás para determinação do Numero Mais Provável (NMP/g ou mL) (APHA, 2001).

Para contagem de Staphylococcus aureus foram pesados $25 \pm 0,2 \mathrm{~g}$ da amostra e adicionado $225 \mathrm{~mL}$ de solução salina peptonada $0,1 \% \quad\left(\mathrm{H}_{2} \mathrm{Op}\right)$, homogeneizados por 60 segundos em homogeneizador tipo stomacher. A partir desta diluição foram efetuadas as demais diluições necessárias. A contagem de Staphylococcus aureus foi realizada em triplicata nas diluições $10^{-1}, 10^{-2}, 10^{-3}, 10^{-4}, 10^{-5}$, na qual $0,1 \mathrm{~mL}$ da amostra foram semeados em Ágar Baird-Parker e as placas incubadas em estufa a $35-37{ }^{\circ} \mathrm{C}$ por $45-48 \mathrm{~h}$. Foram de 3 a 5 colônias típicas (negras brilhantes rodeadas por um alo claro) e atípicas (acinzentadas ou negras sem halo) de cada placa foram repicadas para caldo Infuso Cérebro Coração (BHI) e incubadas a 35$37{ }^{\circ} \mathrm{C} / 18-24 h$. Para a identificação foi realizada com coagulase plasma (APHA, 2001).

Para a pesquisa de Salmonella spp., foram pesados $25 \pm 0,2 \mathrm{~g}$ da amostra e adicionados $225 \mathrm{~mL}$ de solução salina peptonada $1 \%$ tamponada $\left(\mathrm{H}_{2} \mathrm{Op}\right)$, homogeneizados por 60 segundos no stomacher e incubados a $35^{\circ} \mathrm{C} \pm 2{ }^{\circ} \mathrm{C} / 24 \pm 2 \mathrm{~h}$. Posteriormente, foi inoculado simultaneamente $1 \mathrm{~mL}$ desta amostra em tubo contendo caldo tetrationato (TT) que foi incubado a 35 $\pm 2{ }^{\circ} \mathrm{C} / 24 \pm 2 \mathrm{~h}$ e caldo selinito cistina (SC) incubado a 42 $\pm 2{ }^{\circ} \mathrm{C} / 24 \pm 2 \mathrm{~h}$. Em seguida, estas amostras foram estriadas separadamente em Ágar Enterico de Hectoen (HE) Ágar Bismuto Sulfito (BS) e Ágar Xilose Lisina Desoxicolato (XLD) e incubadas a $35 \pm 2{ }^{\circ} \mathrm{C} / 24 \pm 2 \mathrm{~h}$. Colônias características foram confirmadas por testes realizados com Ágar Triplice açúcar Ferro (TSI) e Ágar Lisina Ferro (LIA). Os resultados foram expressos em presença ou ausência de Salmonella spp. (FDA, 2007).

$\mathrm{O} \mathrm{pH}$ foi determinado utilizando-se pHmetro previamente calibrado, introduzindo-se o eletrodo diretamente em $5 \mathrm{~g}$ da amostra homogênea com $50 \mathrm{~mL}$ de água destilada, em triplicata (AOAC, 1995). A acidez titulável foi determinada através de titulação da amostra com hidróxido de sódio N/9 em presença do indicador fenolftaleína e os resultados foram expressos em porcentagem de ácido lático em triplicata, utilizando $5 \mathrm{~g}$ da amostra homogeneizada com $50 \mathrm{~mL}$ de água destilada (AOAC, 1995).

A umidade foi determinada pelo método de secagem em estufa até peso constante, utilizando $5 \mathrm{~g}$ da amostra, todas em triplicata. Procedimentos analíticos recomendados por Aoac (1995). Para a realização da analise de teor de $\mathrm{NaCl}$ utilizou-se $5 \mathrm{~g}$ da amostra diluída em $20 \mathrm{~mL}$ de água destilada, titulada com solução $0,1 \mathrm{M}$ de nitrato de prata $\left(\mathrm{AgNO}_{3}\right)$ em presença do indicador cromato de potássio, método de Mohr (SKOOG, 2005)

Os resultados da caracterização físico-química foram submetidos à Análise de Variância (ANOVA) e teste de média de Tukey, a 5\% de probabilidade utilizando o programa de estatística ASSISTAT versão 7.7 beta. A análise de componentes principais, realizada no sowftare ASSISTAT versão 7.7 beta, foi aplicada para identificar as correlações entre as análises físicoquímicas e posteriormente comparadas com as análises microbiológicas. A porcentagem de explicação foi maior que $70 \%$ nas duas primeiras componentes principais, indicando forte correlação entre as variáveis. A análise multivariada é aplicada nos dados (MARDIA et al., 1979).

\section{Resultados e Discussão}

Quanto à avaliação da conformidade dos dizeres de rotulagem das embalagens de queijos Minas frescal analisadas, foi constatado que $90 \%$ das amostras consideradas industrializadas estavam em acordo com a legislação vigente (Tabela 1). Conforme Lei $\mathrm{n}^{\circ}$ 10.674/03 estabelecida pela ANVISA, $10 \%$ dos rótulos das amostras industriais e $50 \%$ artesanais não apresentavam a expressão "não contém glúten", sem o destaque, nitidez e facilidade de leitura que são exigidos pela legislação. 
Tabela 1: Marcas, temperatura de conservação das amostras nos pontos de venda, conformidade das rotulagens das marcas, e cidades onde foram comercializados os queijos Minas frescal industrializado e artesanal.

\begin{tabular}{ccccc}
\hline Tipo & Marcas & Temperatura de coleta $\left({ }^{\circ} \mathrm{C}\right)^{*}$ & Cidade & Resultado da rotulagem** \\
\hline \multirow{4}{*}{ Industrializado } & $\mathrm{A}$ & 3,5 & Itumbiara & Conforme \\
& $\mathrm{B}$ & 11,1 & Itumbiara & Conforme \\
& $\mathrm{C}$ & 3,8 & Caldas Novas & Conforme \\
& $\mathrm{D}$ & 7,6 & Piracanjuba & Conforme \\
& $\mathrm{E}$ & 11,3 & Goiatuba & Não Conforme \\
\hline \multirow{5}{*}{ Artesanal } & $\mathrm{Aa}$ & 09,9 & Goiatuba & Não Conforme \\
& $\mathrm{Ba}$ & 21,8 & Goiatuba & Não Conforme \\
& $\mathrm{Ca}$ & 20,3 & Itumbiara & Não Conforme \\
& $\mathrm{Da}$ & 20,6 & Itumbiara & Não Conforme \\
& $\mathrm{Ea}$ & 14,5 & Itumbiara & Não Conforme
\end{tabular}

* Temperatura permitida por legislação $<10{ }^{\circ} \mathrm{C} * *$ Legislação utilizada para rotulagem Resolução RDC n. $360 / 2003$.

Na Tabela 1 são apresentadas as marcas, temperatura em que as amostras se encontravam no ponto de venda, no momento da compra e os resultados de conforme ou não conforme da rotulagem dos queijos Minas frescal. Em relação à Instrução Normativa $n^{\circ} 22 / 05,10 \%$ das amostras industriais e $100 \%$ artesanais apresentaram-se em desacordo por não oferecer listagem de ingredientes ou indicação de origem, mas também, especialmente, devido ao prazo de validade estar expresso por período. Segundo a legislação, deve constar pelo menos o dia e o mês para produtos que tenham prazo de validade não superior a três meses ou o mês e o ano para todos os produtos que tenham prazo de validade superior a três meses, também por não conter o selo de Serviço de Inspeção Federal - S.I.F, é de total importância. O selo de fiscalização significa que a fábrica sofre fiscalização do Ministério da Agricultura, Pecuária e Abastecimento MAPA ou das Secretarias Estaduais. Quando o produto não apresenta nenhum tipo de selo, significa que ele não recebe nenhuma fiscalização de órgãos governamentais.

Os resultados referentes à determinação do número mais provável de coliformes totais e coliformes termotolerantes, a contagem de Staphylococcus aureus e Salmonella spp., das amostras de queijo Minas frescal produzidas industrialmente e artesanalmente, comercializadas na região Sul de Goiás, encontram-se na Tabela 2, e posteriormente na Tabela 3 são apresentados os valores permitidos pela legislação vigente.

Os resultados obtidos nas análises microbiológicas pelo Número Mais Provável (NMP/g) de coliformes totais e termotolerantes das amostras do queijo Minas frescal foram detectados em todas as amostras analisadas seguindo o critério especifico da legislação em vigor.

Observa-se na Tabela 2 que as cinco amostras industrializadas (50\%), apresentaram contagem acima do limite máximo permitido para coliformes termotolerantes, e apenas duas amostras artesanais (20\%) estava em desacordo com os padrões estabelecidos, sendo que três dessas amostras artesanais estavam dentro dos padrões exigidos pela ANVISA, conforme a Resolução RDC $\mathrm{N}^{\circ} 12$ de 02/01/2001 e Portaria $\mathrm{N}^{\circ} 146$ de 07/03/1996.

Geralmente, o leite utilizado na fabricação de queijos artesanais não é pasteurizado e no industrializado pode ocorrer recontaminação após a pasteurização devido à manipulação é excessiva e realizada por pessoas sem nenhum conhecimento e/ou cuidado de higiene. $\mathrm{O}$ momento da ordenha também pode ser um importante ponto de contaminação, uma vez que, provavelmente, não há a adequada higienização dos tetos dos animais antes do procedimento (PERRY, 2004).

O resultado acima é semelhante ao encontrado por Araújo et al., (2001), analisando seis amostras de queijo Minas frescal industrializado, verificaram que $50 \%$ estavam com contagens fora do permitido. Louguercio \& Aleixo (2001) estudando o queijo Minas frescal produzido em Cuiabá-MT, demonstraram que 63,3\% das amostras industriais e 15\% artesanais estavam fora dos padrões exigidos para coliformes termotolerantes.

$\mathrm{Na}$ pesquisa de coliformes totais observou-se que todas as amostras $(100 \%)$ de queijo industrializado e artesanal estavam em desacordo com os padrões estabelecidos pela ANVISA, conforme a Resolução RDC $\mathrm{N}^{\circ} 12$ de 02/01/2001 e Portaria ${ }^{\circ} 146$ de 07/03/1996 apresentando valores superiores a $1100 \mathrm{NMP} / \mathrm{g}$. Esses micro-organismos são importantes indicadores das condições de higiene dos processos de fabricação, indicam também, falhas contaminação pós-processo em alimentos pasteurizados, pois os coliformes são facilmente destruídos pelo calor (SILVA, 2008).

Segundo Brant et al. (2007), mesmo a contagem de coliformes totais não sendo exigida pela legislação sanitária vigente para produtos coletados no comércio, esses micro-organismos geralmente são contaminantes ambientais, e a sua contagem elevada indica deficiência na qualidade higiênico-sanitária do produto. Esses pesquisadores analisaram amostras de queijo Minas Artesanal do Serro, e constataram que $80 \%$ das amostras apresentaram coliformes totais acima de $5 \times 10^{3} \mathrm{NMP} / \mathrm{g}$. 
Tabela 2. Resultados das análises microbiológicas referente ao Número Mais Provável (NMP/g) de coliforme totais e termotolerantes, Staphylococcus aureus e ausência e presença de Salmonella spp. dos queijos Minas frescal Industriais e Artesanais.

\begin{tabular}{llllll}
\hline Tipo & Amostra & CT(NMP/g) & CTt(NMP/g) & CSA & Salmonella spp. \\
\hline \multirow{4}{*}{ Industrializado } & $\mathrm{A}$ & $>1,1 \times 10^{5}$ & $>1,1 \times 10^{5}$ & $1,73 \times 10^{3}$ & Ausência \\
& $\mathrm{B}$ & $>1,1 \times 10^{5}$ & $2,1 \times 10^{4}$ & $6,03 \times 10^{5}$ & Ausência \\
& $\mathrm{C}$ & $2,0 \times 10^{3}$ & $2,9 \times 10^{4}$ & $3,96 \times 10^{2}$ & Ausência \\
& $\mathrm{D}$ & $1,5 \times 10^{4}$ & $1,5 \times 10^{4}$ & $2,55 \times 10^{4}$ & Ausência \\
& $\mathrm{E}$ & $1,1 \times 10^{4}$ & $2,1 \times 10^{4}$ & $3,75 \times 10^{5}$ & Ausência \\
\hline \multirow{5}{*}{ Artesanal } & $\mathrm{Aa}$ & $>1,1 \times 10^{5}$ & $3,5 \times 10^{4}$ & $1,72 \times 10^{6}$ & Ausência \\
& $\mathrm{Ba}$ & $>1,1 \times 10^{5}$ & $3,5 \times 10^{4}$ & $7,56 \times 10^{3}$ & Ausência \\
& $\mathrm{Ca}$ & 7,4 & $4,3 \times 10^{4}$ & $3,25 \times 10^{5}$ & Ausência \\
& $\mathrm{Da}$ & 7,4 & $2,1 \times 10^{4}$ & $4,45 \times 10^{6}$ & Ausência \\
& $\mathrm{Ea}$ & 3,6 & $2,1 \times 10^{4}$ & $3,31 \times 10^{6}$ & Ausência \\
\hline
\end{tabular}

Legenda: $\mathrm{CT}=$ coliformes termotolerantes; $\mathrm{CTt}=$ coliformes totais; $\mathrm{SCP}=$ contagem Staphylococcus aureus

Tabela 3. Número Mais Provável de Coliformes totais e termotolerantes, Unidade Formadora de Colônia de Staphylococcus aureus e pesquisa de Salmonella spp. permitido pela legislação estabelecido para Queijo Minas frescal.

\begin{tabular}{cccc}
\hline $\begin{array}{c}\text { NMP/g Coliformes totais } \\
\text { permitido pela legislação }\end{array}$ & $\begin{array}{c}\text { NMP/g Coliformes termotolerante } \\
\text { permitido pela legislação }\end{array}$ & $\begin{array}{c}\text { UFC/g Staphylococcus spp } \\
\text { permitido pela legislação }\end{array}$ & $\begin{array}{c}\text { Pesquisa de Salmonella } \\
\text { spp. }\end{array}$ \\
\hline$\leq 5,0 \times 10^{2} \mathrm{NMP} / \mathrm{g}$ & $\leq 5,0 \times 10^{2} \mathrm{NMP} \cdot \mathrm{g}-1$ & $\leq 5,0 \times 10^{2} \mathrm{UFC} / \mathrm{g}$ & Ausência \\
\hline
\end{tabular}

Os resultados de contagem de Staphylococcus aureus apenas três $(30 \%)$ das amostras apresentaram de acordo com o padrão estabelecido pela ANVISA, conforme Resolução - RDC $\mathrm{n}^{\circ} 12$, de 02 de janeiro de 2001. Os Staphylococcus são bactérias mesófilas apresentando temperatura de crescimento na faixa de 7 ${ }^{\circ} \mathrm{C}$ a $47,8{ }^{\circ} \mathrm{C}$ as enterotoxinas são produzidas entre $10{ }^{\circ} \mathrm{C}$ e $46{ }^{\circ} \mathrm{C}$, com ótimo entre $37{ }^{\circ} \mathrm{C}$. Estas bactérias são tolerantes a concentrações de $10 \%$ a $20 \%$ de $\mathrm{NaCl}$ e a nitratos. Em relação ao $\mathrm{pH}$, Staphylococcus aureus proliferam na faixa de 4,0 a 9,8, com ótimo entre 6,0 e 7,0. Amostras de nove queijos Minas frescal coletadas por Isepon et al. (2003) apresentaram média para contagem de Staphylococcus aureus de $1,95 \times 10^{6}$ a $6,5 \times 10^{7} \mathrm{UFC} / \mathrm{g}$. Em amostras de queijos Minas frescal analisadas por Hoffmann et al., (2002), houve uma variação de $4,8 \times 10^{7}$ a $2,8 \times 10^{12} \mathrm{UFC} / \mathrm{g}$ para este mesmo micro-organismo.

Os resultados microbiológicos revelaram ausência de Salmonella spp., em todas as amostras analisadas, em concordância com a legislação vigente. Esses resultados foram semelhantes a diversos estudos como, no trabalho realizado por Callon et al (2011), que realizaram queijos Minas frescal e nenhuma amostra apresentou Salmonella spp. A contaminação com Salmonella spp., pode estar relacionada a diferentes fontes, porém, a pasteurização é capaz de eliminá-la. No queijo Minas frescal, a contaminação pode estar relacionada à ineficiência da pasteurização, manipuladores da fábrica portadores, da doença ou da utilização de água não potável no processamento (TORTORA et al., 2000).
Pode-se observar que houve uma maior contagem do grupo de coliformes e menor de Staphylococcus aureus e isso ocorre, pois, os coliformes competem com as bactérias lácticas quando o $\mathrm{pH}$ é elevado e a temperatura é adequada. Por isso, apresentam um aumento durante os primeiros os primeiros dias. Brooks et al. (2011) avaliaram amostras de queijos produzidos com leite cru e encontraram 7,3\% das amostras contaminadas por Staphylococcus aureus, sendo que apenas uma amostra apresentava valor acima de $10^{3} \mathrm{UFC} / \mathrm{g}$ e contagem elevada de coliformes.

Na Tabela 4 estão demonstrados os valores médios encontrados nas análises físico-químicas do queijo Minas frescal industrializado, os valores referentes ao queijo Minas frescal artesanal. Comparando os dois tipos de queijos (industrial e artesanal), de acordo com as médias gerais, observaram-se que os teores de $\mathrm{pH}$, acidez, umidade e teor de $\mathrm{NaCl}$ foram estatisticamente diferentes $(\mathrm{P} \leq 0,05)$.

Os valores de $\mathrm{pH}$ são adotados na produção queijeira para realizar um controle durante seu processamento. $\mathrm{O}$ $\mathrm{pH}$ das amostras analisadas variou entre 4,3\% a 6,7 \%, sendo que estes valores apresentaram diferença significativa $(\mathrm{P} \leq 0,05)$ entre as 10 amostras. Essa variação ocorreu devido ao tempo e temperatura de armazenamento nos expositores dos supermercados, pois os queijos industrializados foram avaliados entre 10 dias de armazenamento, mas se encontraram estáveis comparados aos resultados determinados por Silva (2008). 
Tabela 4. Resultados das análises físico-químicas ( $\mathrm{pH}$, acidez, umidade e teor de $\mathrm{NaCl}^{3}$ ) dos queijos Minas frescal artesanais (A,B,C,D,E) e industriais (Aa,Ba,Ca,Da,Ea).

\begin{tabular}{|c|c|c|c|c|c|}
\hline Tipo & Amostra & $\mathrm{pH}$ & Acidez ${ }^{1}$ & Umidade $^{2}$ & Teor de $\mathrm{NaCl}^{3}$ \\
\hline \multirow{5}{*}{ Industrializado } & A & $5,76 \pm 0,02^{\mathrm{d}}$ & $0,30 \pm 0,01^{\mathrm{d}}$ & $56,8 \pm 0,50^{\mathrm{c}}$ & $1,3 \pm 0,26^{\mathrm{ab}}$ \\
\hline & B & $5,6 \pm 0,02^{\mathrm{d}}$ & $0,52 \pm 0,0^{\mathrm{d}}$ & $57,9 \pm 0,10^{\mathrm{b}}$ & $1,3 \pm 0,09^{\mathrm{ab}}$ \\
\hline & $\mathrm{C}$ & $6,37 \pm 0,03^{\mathrm{c}}$ & $0,17 \pm 0,02^{\mathrm{a}}$ & $69,5 \pm 0,22^{\mathrm{d}}$ & $1,1 \pm 0,07^{\mathrm{abc}}$ \\
\hline & $\mathrm{D}$ & $4,3 \pm 0,01^{\mathrm{f}}$ & $0,68 \pm 0,02^{\mathrm{b}}$ & $64,9 \pm 1,32^{\mathrm{a}}$ & $1,2 \pm 0,07^{\mathrm{abc}}$ \\
\hline & E & $6,7 \pm 0,02^{\mathrm{a}}$ & $0,10 \pm 0,00^{\mathrm{d}}$ & $65,3 \pm 0,74^{\mathrm{d}}$ & $1,4 \pm 0,16^{\mathrm{a}}$ \\
\hline \multirow{5}{*}{ Artesanal } & $\mathrm{Aa}$ & $6,2 \pm 0,01^{\mathrm{c}}$ & $0,18 \pm 0,03^{\mathrm{d}}$ & $57,2 \pm 1,37^{\mathrm{d}}$ & $1,4 \pm 0,06^{\mathrm{abc}}$ \\
\hline & $\mathrm{Ba}$ & $5,4 \pm 0,02^{\mathrm{e}}$ & $0,52 \pm 0,08^{\mathrm{d}}$ & $56,0 \pm 0,31^{\mathrm{b}}$ & $1,2 \pm 0,06^{\mathrm{abc}}$ \\
\hline & $\mathrm{Ca}$ & $6,7 \pm 0,06^{\mathrm{a}}$ & $0,14 \pm 0,02^{\mathrm{bc}}$ & $63,7 \pm 0,68^{\mathrm{d}}$ & $0,9 \pm 0,12^{\text {cd }}$ \\
\hline & $\mathrm{Da}$ & $6,5 \pm 0,02^{\mathrm{b}}$ & $0,14 \pm 0,00^{\mathrm{c}}$ & $61,5 \pm 1,19^{\mathrm{d}}$ & $0,7 \pm 0,08^{\mathrm{d}}$ \\
\hline & $\mathrm{Ea}$ & $6,5 \pm 0,07^{b}$ & $0,57 \pm 0,00^{\mathrm{bc}}$ & $63,3 \pm 0,72^{\mathrm{d}}$ & $1,0 \pm 0,04^{\mathrm{bcd}}$ \\
\hline
\end{tabular}

${ }^{1}$ Valores de acidez expressos em $\mathrm{mg} / \mathrm{g}$ de ácido lático representados por média \pm desvio-padrão. ${ }^{2}$ Valores de umidade expressos em (\%) de base úmida. ${ }^{3}$ Valores de Teor de $\mathrm{NaCl}$ expressos em $\mathrm{g} / \mathrm{mL}$ de cloreto de sódio. Letras diferentes entre as colunas diferem significativamente pelo teste Tukey $(\mathrm{P} \leq 0,05)$.

Valores semelhantes encontrado por Buriti et al. (2005) estudou o queijo Minas frescal por um período de 21 dias armazenado à temperatura de $8{ }^{\circ} \mathrm{C}$, também observou uma redução no pH de 6,16 a 5,38 (diferença de 0,78 ) entre o $1^{\circ}$ dia e o $21^{\circ}$ dia de armazenamento.

Dependendo das condições da temperatura que estão expostos, os queijos podem sofrer alterações tornando-se mais ácidos. No estudo realizado por Ricardo et al (2011), os queijos analisados apresentaram acidez variando entre 0,10 a 0,68 para os industrializados e 0,14 a 0,57 para os artesanais.

Em relação ao teor de umidade, todas as amostras apresentaram valores acima de 55\%, caracterizando-as como previsto na Instrução Normativa $n^{\circ} 4$ de 2004 do Ministério da Agricultura, Pecuária e Abastecimento (MAPA), como queijos de muito alta umidade. Valores semelhantes foram obtidos nos queijos Minas frescal avaliados por Ribeiro (2011).

O teor de cloreto de sódio constitui um dos aspectos da tecnologia que influenciam a qualidade do queijo, ao desempenhar várias funções como proteção contra microorganismos indesejáveis, complementação da dessoragem contribuindo para a formação da casca, efeito potenciador do sabor, regulação da maturação e solubilização das proteínas melhorando a textura do queijo. Para os teores de $\mathrm{NaCl}$ houve uma variação significativa entre $0,7 \%$ a $1,4 \%$, resultados pouco maiores foram encontrados por Aguiar et al (2013), onde estabelecem um percentual próximo a $2-2,5 \%$ de cloreto de sódio que é equivalente a uma concentração na fase aquosa de 4 a $5 \%$, valores suficientes para que ocorra a inibição do desenvolvimento da maioria das bactérias lácticas.

$\mathrm{Na}$ Figura 1 está representado pela análise de componentes principais das análises físico-químicas realizadas nas amostras de queijos industrializados e artesanais.

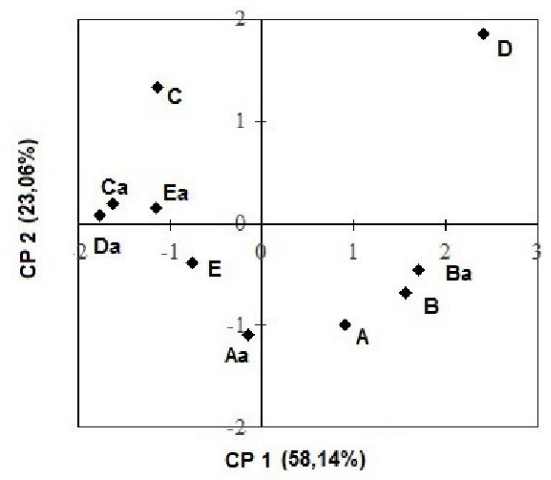

Figura 1. Análise dos componentes principais das análises físico-químicas das marcas dos queijos Minas comercializados artesanalmente (Aa, Ba, Ca, Da, Ea) e industrializado (A, B, C, D, E).

A CP1 é explicada pelas análises de $\mathrm{pH}$ e acidez (g/100g de ácido lático) (cargas fatoriais $\geq 0.7$ destas variáveis $\mathrm{CP} 1$, sendo todas essas variáveis correlacionadas positivamente (Figura 1). A CP2 é explicada pela análise de teor de umidade (\%) e o teor de sal, sendo que eles correlacionaram negativamente entre si.

Pode- se observar na Figura 1 que formaram dois grupos de amostras segundo as características físicas e químicas dos queijos Minas frescal: Grupo 1 (A, B, Ba) e Grupo 2 (Ca, Da, Ea e E). As amostras do Grupo 1 apresentaram valores menores de $\mathrm{pH}$, na faixa entre 5,49 e 5,76 e menor teor de umidade, entre 56,05 a $57,92 \%$, e uma alta contagem de coliformes totais, neste caso houve a multiplicação dos micro-organismos com valores reduzidos de $\mathrm{pH}$ e umidade. Isso pode ter ocorrido devido a presença da E. coli, pois, segundo Furtado (1999), a E. coli fermenta a lactose diminuindo os valores de $\mathrm{pH}$. Resultados semelhantes, quanto à redução de $\mathrm{pH}$ nos queijos com a presença da $E$. coli, 
também foram observados por Kousta, (2010) que avaliaram o $\mathrm{pH}$ de sete marcas do queijo Minas frescal comercializados em São Paulo, e que seis marcas continham níveis altos de coliformes e constatando acentuada redução do $\mathrm{pH}$, aos 21 dias de armazenamento, nos queijos comercializados que continham níveis altos de coliformes.

As amostras do Grupo 2 apresentaram valores maiores de $\mathrm{pH}$, na faixa entre 6,51 a $6,76 \%$ e menor teor de acidez, entre 0,10 a $0,15 \mathrm{~g} / 100 \mathrm{~g}$ de ácido lático (Tabela 3 e 4), com uma elevada contagem de Staphylococcus aureus.

A forte correlação positiva encontrada na CP1 entre pH e acidez está relacionada com a multiplicação dos micro-organismos, onde os valores de acidez e $\mathrm{pH}$ do queijo tendem a aumentar com a multiplicação dos micro-organismos no decorrer do período de armazenamento, beneficiando o produto por inibir a microbiota patogênica.

\section{Conclusões}

Os resultados microbiológicos obtidos no presente trabalho revelam que a maioria dos queijos analisados se apresentavam em desacordo com a legislação vigente, confirmando possíveis falhas no controle da qualidade do queijo, procedimentos higiênicos inadequados durante a fabricação, manutenção em temperaturas inadequadas e uso de matéria prima de baixa qualidade higiênico-sanitária. Por tanto, por não ser maturado e ser perecível, deve ser consumido rapidamente, após curta estocagem em ambiente refrigerado.

A produção artesanal também exige atenção fiscalizadora, onde o mais importante é, antes de tudo, a orientação e o treinamento dos fabricantes, quanto aos métodos higiênico-sanitários a serem adotados no estabelecimento.

As análises efetuadas evidenciaram a ocorrência de possíveis de falhas no controle da qualidade de queijos submetidos ao Serviço de Inspeção Federal (SIF), havendo a necessidade de uma constante e efetiva fiscalização do produto e da matéria-prima, visando assim, garantir a qualidade e segurança do produto disponibilizado ao consumidor.

\section{Referências Bibliográficas}

AGUiAR, V. C; TORRES, B. T; SOUSA, C. D. Aspectos físico-químicos, bioquímicos e microbiológicos da maturação de queijos de coalho produzidos com leite bovino. Revista Brasileira de Pesquisa em Alimentos, Campo Mourão-PR, v. 3, n. 2, p. 99-102, 2013.

APHA. AMERICAN PUBLIC HEATH ASSOCIATION Enterobacteriase, coliforme, and Escherichia coli as quality and safety indicators. In: DOWNES, F. P.; ITO, K. (ed.). Compendium of Methods for the Microbiological Examination of Foods, $4^{\mathrm{a}}$ ed. Washington: American Public Heath Association, v. 3, n. 8, p. 69-82, 2001.

ARAÚJO, W. N.; SILVA, M. N.; W.N; MARTINEZ, T. C.; SILVEIRA, V. F.; BARROS, S. L. B; SILVA, A. V. A. F. Isolamento e identificação de coliformes no queijo Minas comercializado na região metropolitana de Salvador/Bahia Revista Brasileira Saúde Produção Animal, Salvador-BA, v.43, n. 2, p. 37-42, 2001.

AOAC. ASSOCIATION OF OFFICIAL AGRICULTURAL CHEMISTS. Official methods of the Association of the Agricultural Chemists. $16^{\mathrm{a}}$ ed. Washington: DC, 1995. v. 2, $1094 \mathrm{p}$.

BRANT, L. M. F., FONSECA, L. M., SILVA, M. C. C. Avaliação da qualidade microbiológica do queijo Minas Frescal do Serro - MG. Arquivo Brasileiro Medicina Veterinaria e Zootecnia, Belo Horizonte- MG, v. 59, n. 6, p. 1570-1574, 2007.

BRASIL/MAPA. MINISTÉRIO DA AGRICULTURA, PECUÁRIA E ABASTECIMENTO. Portaria ${ }^{\circ} 146$ de 07 de março de 1996. Aprova os Regulamentos Técnicos de Identidade e Qualidade dos Produtos Lácteos. Diário Oficial [da República Federativa do Brasil]. Brasília, DF, em 07 mar. 1996.

BRASIL/ANVISA. AGÊNCIA NACIONAL DE VIGILÂNCIA SANITÁRIA. Resolução $\mathbf{n}^{0} 12$ de 02 de Janeiro de 2001. Regulamento Técnico sobre Padrões Microbiológicos para Alimentos. Brasília-DF, 2001.

BRASI/MINISTÉRIO DA SAÚDE. Revoga portaria n. 451, de 19 de setembro de 1997. Resolução - RDC n. 12, 2 de janeiro de 2001. Diário Oficial [da República Federativa do Brasil], Brasília-DF, Art. 4, p.1-48, de 10 jan. 2001.

BRASIL/ANVISA. AGÊNCIA NACIONAL DE VIGILÂNCIA SANITÁRIA. Lei Federal $\mathbf{n}^{\circ} \mathbf{1 0 . 6 7 4}$, de 16 de maio de 2003. Diário Oficial [da República Federativa do Brasil]. Brasília, DF, 2003.

BRASIL/MAPA. MINISTÉRIO DA AGRICULTURA PECUÁRIA E ABASTECIMENTO. Instrução Normativa $N^{\circ} 4$ de 01 de março de 2004. Regulamento técnico para fixação de identidade e qualidade do queijo minas frescal. Brasília, DF, MAPA, 5 mar. 2004

BRASIL/MAPA. MINISTÉRIO DA AGRICULTURA, PECUÁRIA E ABASTECIMENTO. Instrução Normativa $n^{\circ}$ 22 , de 24 de novembro de 2005.. Diário Oficial [da República Federativa do Brasil]. Brasília, DF, 25 nov. 2005. Seção 1, n 226. p. 15-6.

BROOKS, J. C. MARTINEZ, B.; STRATTON, J.; BIANCHINI, A.; KROKSTROM, R.; HUTKINS, R. Survey of raw milk cheeses for microbiological quality and prevalence of foodborne pathogens. Food Microbiology, London, v. 31, n. 5, p. 154-158, 2011.

BURITI, F. C. A.; ROCHA, J. S.; SAAD, S. M. I Incorporation of Lactobacillus acidophilus in Minas fresh cheese and implicatons for textural and sensorial properties during storage. International Dairy Journal, Campinas-SP, v. 15, n. 12 , p. $1279-1288,2005$ 
CARVALHO, J. D. G.; VIOTTO, W. H.; KUAYE, A. Y. The quality of Minas Frescal cheese produced by different technological processes. Food Control, v. 18, n, 1. p. 262267, 2007.

CALLON, C.; PICQUE, D.; CORRIEU, G.; MONTEL, M. C. Ripening conditions: a tool for the control of Listeria monocytogenes in uncooked pressed type cheese. Food Control, v. 22, n. 12, p. 1911-1919, 2011.

FDA/CFSAN. FOOD AND DRUG ADMINISTRATION, CENTER FOR FOOD SAFET \& APPLIED NUTRITION. Foodborne Pathogenic Microorganisms and Natural Toxins Handbook "Bad Bug Book". December 2, 2007.

FURTADO, M. M. Problemas típicos do queijo minas frescal. Principais problemas dos queijos: causas e prevenção. São Paulo-SP: Fonte de comunicações, 1999. p. $155-160$.

HOFFMANN, F. L.; SILVA, J. V.; VINTURIM, T. M. Qualidade microbiológica de queijos tipo "minas frescal", vendidos em feiras livres na região de São José do Rio Preto, SP. Higiene Alimentar, Mirandópolis-SP, v. 16, n. 96, p. 69$76,2002$.

ISEPON, J. S.; SANTOS, P. A.; SILVA, M. A. P. Avaliação microbiológica de queijos Minas Frescal comercializados na cidade de Ilha Solteira - SP. Revista Higiene Alimentar, Campinas-SP, v.17, n. 106, p. 89-94, 2003.

KOUSTA, M.; MATARAGAS, M.; SKANDAMIS, P.; DROSINOS, E. H. Prevalence and sources of cheese contamination with pathogens at farm and processing levels. Food Control, v. 21, n. 6, p. 805-815, 2010.

LOUGUERCIO, A. P.; ALEIXO, J. A. G. Microbiologia de Queijo tipo Minas Frescal Produzido Artesanalmente. Revista Ciência Rural, Curitiba-PR, v. 31, n. 6, p. 120, 2001.

MARDIA, K. V.; KENT, J. T.; BIBBY, J. M. Multivariate analysis. London: Academic Press, 1979. p. 518.
OLIVEIRA, L. E.; SILVA, C. O.; PASCOAL, G. B. Comparação entre a composição nutricional dos rótulos e as análises laboratoriais de queijos minas frescal (tradicional e light). Revista Instituto Laticínios Cândido Tostes, Juiz de Fora-MG, v. 69, n. 4, p. 280-288, 2014.

PERRY, K. S. P. Queijos: aspectos químicos, bioquímicos e microbiológicos. Quimica Nova, São Paulo-SP, v. 27, n. 2, p. 293-300, 2004.

RIBEIRO, E. P.; SIMÕES, L. G.; JURKIEWICZ, C. H. Desenvolvimento de queijo minas frescal adicionado de Lactobacillus acidophilus produzido a partir de retentados de ultrafiltração. Ciência Tecnologia Alimentos, Campinas-SP, v. 29, n. 1, p. 19-23, 2009.

RICARDO, N. R. SOUZA, J. F.; GODOI, F. S.; PRADO, J. $\mathrm{V}$.; Análise físico-química de queijos minas frescal artesanais e industrializados comercializados em Londrina-PR. Revista Brasileira de Pesquisa em Alimentos, Campo Mourão-PR, v. 2, n. 2, p. 89-95, 2011.

SENA, M.J.; CERQUEIRA, M.M.O.P.; MORAIS, C.F.A.; CORRÊA, E.S.; SOUZA, M.R. Características físico-químicas de queijo de coalho comercializado em Recife-PE. Higiene Alimentar, São Paulo-SP, v. 14, n.74, p. 41-44, 2000.

SILVA, N.; JUNQUEIRA, V. C. A.; SILVEIRA, N. F. A. Manual de métodos de análises microbiológicas de alimentos. São Paulo-SP: Livraria Varela, 2001. 317p.

SILVA, T. V. Caracterização físico-química de queijos tipos Minas Frescal produzidos por pequenos produtores do município de Guarapuava e região. Salão de Extensão e Cultura, v. 4, n. 6, p. 35, 2008.

SKOOG, D. A.; WEST, D. M.; HOLLER, F. J.; CROUCH, S. R. Fundamentos de Química Analítica, São Paulo-SP: Thomson, 2005, 200p.

TORTORA, G. J.; FUNKE, B. R.; CASE, C. L. Microbiologia. Porto Alegre-RS: Artmed, 2000. 827p. 